\title{
Enunciación
}

\section{Categorías culturales en la instrumentalización del proceso lector y escritor}

\section{Cultural categories in the instrumentalisation of the reading and writing process}

\author{
Doris Vanegas Vanegas $^{* \mathbb{D}}$, Aura Alexandra Ramón Vanegas ${ }^{* * \mathbb{C}}$
}

\section{Resumen}

La forma como organizamos el conocimiento del mundo en categorías y lo expresamos a través del lenguaje influye en la calidad del proceso lector y escritor. No obstante, se da por obvio el reconocimiento y uso de las categorías, sin detenerse en ellas durante la mediación de la lectura y la escritura; hecho que afecta su instrumentalización cognitiva. Concebir categorías culturales como nociones de un sistema, un factor, una clasificación, una función, por ejemplo, no siempre se da por sí mismo. Motivo por el cual, en la fundamentación teórica y metodológica de las categorías propuestas, se ha tenido en cuenta el reconocimiento del imaginario cultural, el pensamiento categorial, y la delimitación de funciones cognitivas de entrada, de elaboración y de salida, propuestas por Feuerstein (1993) como vía para la instrumentalización cognitiva que se evidencia en la lectura y la escritura. Una heurística de la realidad y del lenguaje como metodología ha facilitado la precisión y el estudio de las categorías culturales. Ya es conocida la utilidad de las herramientas cognitivas como mapas conceptuales y mentefactos; pero, sin duda, las categorías culturales también ayudan en la instrumentalización cognitiva de la lectura y la escritura, esenciales en la formación investigativa y profesional. Los resultados se evidencian en el inventario de categorías culturales, en su clasificación y en cómo favorecen la instrumentalización de las funciones cognitivas presentes en la lectura y la escritura. Las categorías culturales también viabilizan la instrumentalización del lenguaje y de la cultura.

Palabras claves: categorías, cultura, imaginario, lectura, escritura.

\begin{abstract}
How we organise the world's knowledge into a hierarchy and express it through language influences the quality of the reading and writing process. Nonetheless, identifying and using the categories are processes that are unnoticed and not paid attention to while reading and writing, which affects cognitive instrumentalisation. Understanding cultural categories as the notions of a system, a factor, a classification or of a function, for example, does not always occur by itself. Thus, the theoretical and methodological foundations of the proposed categories have considered identifying the cultural imaginary, the categorical thinking and the delimitation of cognitive functions at the input, development and output levels, proposed by Feuerstein (1993) as a method for cognitive instrumentalisation that becomes evident in reading and writing. Heuristics of reality and language as a methodology has facilitated the precision and study of cultural categories. The usefulness of the cognitive tools as concept maps and mentifacts is already known. However, cultural categories are also clearly an aid in the cognitive instrumentalisation of reading and writing, which are essential for research and professional training. The results are evident in cultural categories' inventory and classification and how they favour the instrumentalisation of the cognitive functions present in reading and writing. In addition, cultural categories make language and culture instrumentalisation viable.
\end{abstract}

Keywords: categories, culture, imaginary, reading, writing.

\footnotetext{
* Doctora en Didáctica de las Lenguas y sus Culturas, Universidad de Murcia (España). Docente de la Universidad de Pamplona (Colombia). Correo electrónico: dvanegas@unipamplona.edu.co

** Ingeniera Química, Universidad Industrial de Santander (Colombia). Docente de la Universidad de Pamplona (Colombia). Correo electrónico: auralexa@ hotmail. com
}

Cómo citar este artículo: Vanegas, D. y Ramón, A.A. (2019). Categorías culturales en la instrumentalización del proceso lector y escritor. Enunciación, 24(2), 267-275. DOI: http://doi.org/10.14483/22486798.14137

Artículo recibido: 23 de noviembre de 2018; aprobado: 24 de abril de 2019 


\section{Introducción}

La forma como se desarrolla el pensamiento, el lenguaje y la cultura desde una concepción categorial y gramatical, y el modo como se materializan en las funciones cognitivas del individuo influyen en la conformación del imaginario cultural evidente en códigos cada vez más elaborados (Feuerstein, 1993; Feuerstein, citado por Martínez, 1988) con los que se abordan procesos complejos como la lectura y la escritura que considera de lo literal e inferencial a lo crítico intertextual, y de la coherencia y cohesión a lo pragmático (MEN, 1998). Por consiguiente, contribuir a la instrumentalización del pensamiento categorial, como uno de los retos de las funciones cognitivas, puede coadyuvar, así mismo, a la instrumentalización cognitiva, lingüística y cultural de dichos procesos. Término que implica abstraer, representar, relacionar, inferir, cuestionar, generalizar, conceptos (Feuerstein, 1993; Feuerstein, citado por Martínez, 1988). En este sentido, surge la pregunta problema: ¿Cómo instrumentalizar el proceso lector y escritor en relación con el desarrollo del pensamiento y la apropiación del conocimiento?

Para esta labor, como se explicitará en la metodología, se proyectó la elaboración de un inventario y una propuesta de clasificación de un conjunto de elementos textuales frecuentes que se precisó bajo la denominación de categorías culturales.

Respecto a la fundamentación teórica y metodológica de las categorías propuestas, se hace referencia al reconocimiento del imaginario cultural (Vanegas y Ramón, 2017), al pensamiento categorial, la delimitación de funciones cognitivas de entrada, de elaboración y de salida propuestas por Feuerstein (1993 citado por Martínez, 1988) que se refieren respectivamente a cantidad $y$ calidad de los datos acumulados por el individuo antes de enfrentarse a la solución de un problema o de una situación; la organización y estructuración de la información en la solución de problemas; y, la comunicación exacta y precisa de la respuesta o solución del problema. También se relaciona con la labor hermenéutica que toma como base el trabajo con categorías. No obstante, se es consciente del origen de tratamiento categorial desde Aristóteles (s.f.) y el reconocimiento de categorías de la realidad en relación con categorías gramaticales. Aspecto esencial, porque las categorías se organizan y logran generar gramáticas específicas.

Puede decirse que se echa una red específica de gramáticas textuales que responden en el caso de las categorías culturales a una gramática cultural general: ¿Qué dice? ¿Esto a qué corresponde? ¿A qué se está refiriendo?, elementos que buscan dar claridad sobre un concepto o definir o teorizar, y son categorías de carácter transdisciplinar, inferencial y coadyuvante de otras categorías y gramáticas. Se toma un texto base, a modo de ejemplo, para mostrar en este la coexistencia de diversas gramáticas.

La aplicación de las categorías culturales se evidencia en el desarrollo de mentefactos, organigramas temáticos y diagramas de flujo, entre otros. Se presenta un mentefacto, precisamente, de las categorías culturales para dar cuenta de su comportamiento.

Por último, se presenta este estudio como forma de instrumentalización de la lectura y la escritura, por cuanto favorece una lectura más consciente que a su vez permite la apropiación e instrumentalización del conocimiento, el análisis hermenéutico, la implementación de planes de escritura favorecedores del desarrollo textolingüístico, la metacognición, la construcción de un código elaborado y el empoderamiento lectoescritor que se busca en la academia.

\section{Conceptualización y aplicación}

\section{Categorías culturales}

Desde un método heurístico (Vanegas y López, 2015a) se puede llegar a explicar ¿qué son las categorías culturales?, ¿cuál es su sustento teórico-filosófico?, ¿cómo se presentan y qué 
procesos favorecen?, ¿cómo se clasifican?, ¿para qué sirven?, ¿cuál es su papel en la lectura y la escritura? Estrategia a través de preguntas que permiten profundizar en un objeto de estudio. Sin embargo, dicho cuestionamiento requiere de puntos de partida, como las categorías si se quiere instrumentalizar verdaderamente el proceso lector y escritor.

Paralelamente, desde una metodología interdisciplinar (Vanegas, Celis y Becerra, 2016) se concibe el objeto de estudio de forma compleja y, desde la metodología cultural (Vanegas, Ramón y Valencia, 2015), el proceso de instrumentalización de dicho objeto a partir de la activación de funciones como la representativa, la codificadora, la identitaria, la contextualizadora, la entronizadora, la patrimonial y, obviamente, la instrumentalizadora. Interdisciplinariedad y cultura que están presentes en las funciones cognitivas estudiadas por Feuerstein y se pueden materializar en estructuras mentefactuales.

Al respecto, es posible presentar la concepción de unas categorías culturales dispuestas a modo de mentefacto con el fin de facilitar su reconocimiento, su relación e implicación (figura 1).

\section{Imaginario cultural e instrumentalización cognitiva lectora}

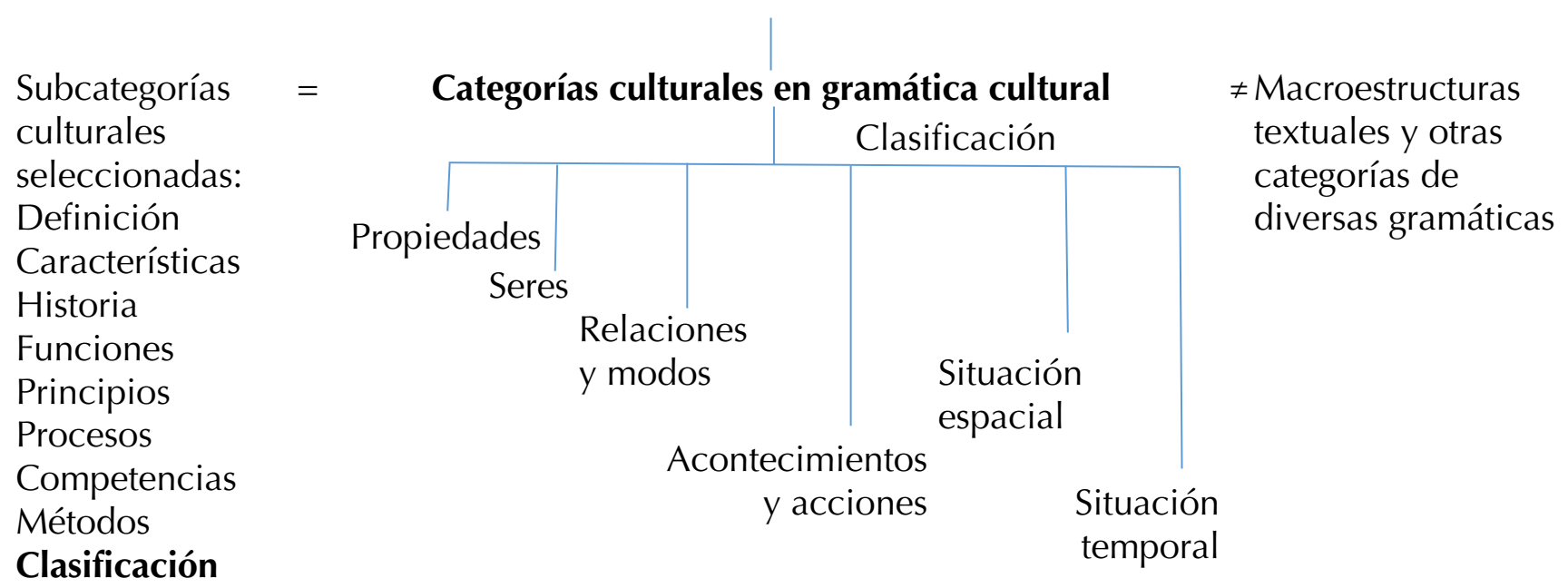




\section{Desarrollo de subcategorías seleccionadas:}

Definición y características. Las categorías culturales son nociones que forman parte del pensamiento humano; logran configurar una gramática cultural general (qué se dice); y, se caracterizan por su poder representacional, inferencial, transdisciplinar y coadyuvante.

Historia. Aristóteles fue quien propuso las categorías y se ocupó de clasificarlas:

Cada una de las palabras o expresiones independientes o sin combinar con otras significan de suyo una de las siguientes cosas: el qué (la sustancia), la magnitud (cantidad), qué clase de cosa es (cualidad), con qué se relaciona (relación), dónde está (lugar), cuándo (tiempo), en qué actitud está (posición, hábito), cuáles son sus circunstancias (estado, hábito, condición), su actividad (acción), su pasividad (pasión). Del libro de las Categorías, capítulo 4.

Se siguió con una orientación lingüística en la que se correlacionaron categorías gramaticales con categorías de la realidad; en un momento, con una concepción saussureana binaria del signo, y trípode, para el caso de Peirce: "el signo se une con su objeto por un acto mental, acto ya habitualizado por alguna convención. De esta manera, el símbolo, como portero más apropiado de la terceridad, pasa de signo arbitrario a signo necesario dentro de un contexto cultural determinado" (estudiado por Merrell, s.f.). La Psicología y la Filosofía, cada una por su parte, también prosperaron investigaciones y teorías como las categorías de Kant (Montero, 1976) y el interaccionismo simbólico de Blumer resumido por Carabaña y Lamo (1978): "el universo de símbolos internalizados que surge de la interacción sirve de mediación"; en consecuencia, "lo que signifiquen las cosas para el sujeto va a depender de su interacción social con otros actores de su entorno y, en definitiva, de los significados aprendidos en su experiencia social interactiva" (Blumer, 1937, citado por Pons, 2010); otros trabajos como las figuras de lo pensable, por Cornelius Castoriadis (2002), analizan contenidos culturales e incertidumbres sociales relacionados con el imaginario. "la historia de la humanidad es la historia del imaginario humano y de sus obras. Historia y obras del imaginario radical, que aparece apenas existe una colectividad humana". Por consiguiente, la concepción de categorías culturales que configuran una gramática en un imaginario cultural se ha mantenido a lo largo del tiempo y se ha ido complejizando.

Funciones. Las categorías culturales (qué se dice) inciden en la configuración de un imaginario cultural e instrumentalización cognitiva, consecuente con un contexto cultural, Ilámese primario o secundario en términos de Bajtín (2011), categorías relacionadas con una gramática lingüística y/o textual (en qué lo dice) y con una gramática cognitiva (con qué lo dice).

En resumen, las categorías culturales favorecen las funciones culturales que se precisan en representativa, instrumentalizadora, codificadora, identitaria, contextualizadora, entronizadora y patrimonial.

Principios. Las categorías culturales pueden estar orientadas por la inferencialidad, la invariabilidad, con margen de sinonimia, y la generalización. Esto, por cuanto su comportamiento suele estar presente en contenidos implícitos; admite la puntualización de categorías con significado similar como localización respecto a ubicación o situación geográfica; acepciones que coinciden en un concepto general que desambigua el texto en cuestión.

Procesos y competencias. Tradicionalmente relacionadas la lectura y la escritura, y su instrumentalización, con el aprendizaje del estudiante, quien, si se deja a libre albedrío, no logra apropiarse de los contenidos curriculares culturales de forma fácilmente recuperable. El desarrollo de una competencia textolingüística (López, Vanegas y López, 2007), el uso de una función heurística (Halliday, 2013) y el desarrollo cognitivo (De Zubiría, 1988), están íntimamente relacionados con el reconocimiento y uso de las categorías culturales.

Métodos. Las categorías culturales pueden ser material importante para la aplicación de métodos como el heurístico (Vanegas y López, 2015a; 2015b), el hermenéutico (Martínez, 2002), el interdisciplinar (Vanegas, Celis y Becerra, 2016) y el cultural (Vanegas, Ramón y Valencia, 2015).

Clasificación. Acoge categorías aristotélicas y kantianas y propone incluir la categoría de acontecimientos. Esta clasificación y su desglose se presenta en un organigrama temático que permite tomar conciencia de las categorías como un constructo esencial para el abordaje de la lectura y la escritura de forma más puntual y con posibilidad de una mejor instrumentalización de estas.

Figura 1. Mentefacto sobre categorías culturales

Fuente: elaboración propia.

Una propuesta de clasificación de las categorías culturales la encontramos en la figura 2.

La precisión de estas categorías, sin duda, favorecen la instrumentalización cognitiva de la lectura y la escritura por cuanto resuelven situaciones como el qué leer y escribir, cómo leer y escribir, para qué leer y escribir, con qué leer y escribir. Estos elementos trascienden la gramática lingüística hacia una gramática textual (Van Dijk, 1980) y cultural de carácter más general: qué dice/digo, cómo dice/digo, para qué dice/digo, con base en qué dice/digo... 
Heurística de la realidad a partir de la interacción de categorías culturales

\begin{tabular}{|c|c|c|c|c|c|}
\hline (PROPIEDADES) & SERES & $\begin{array}{l}\text { RELACIONES } \\
\text { Y MODOS }\end{array}$ & $\begin{array}{c}\text { ACONTECIMIENTOS } \\
\text { Y ACCIONES }\end{array}$ & $\begin{array}{l}\text { SITUACIÓN } \\
\text { ESPACIAL }\end{array}$ & $\begin{array}{l}\text { SITUACIÓN } \\
\text { TEMPORAL }\end{array}$ \\
\hline $\begin{array}{l}\text { Noción } \\
\text { representación } \\
\text { perceptibilidad } \\
\text { objetivo } \\
\text { características: } \\
\text { percepción } \\
\text { funciones } \\
\text { ubicación } \\
\text { ambiente } \\
\text { contexto } \\
\text { condiciones } \\
\text { espaciales } \\
\text { temporales } \\
\text { definición } \\
\text { origen } \\
\text { evolución } \\
\text { composición } \\
\text { partes/element. } \\
\text { estructuración } \\
\text { niveles } \\
\text { técnicas } \\
\text { criterios } \\
\text { habilidades } \\
\text { sostenimiento } \\
\text { alimentación } \\
\text { funcionamiento/ } \\
\text { comportamiento } \\
\text { procesos y } \\
\text { etapas } \\
\text { medición } \\
\text { formas y estilos } \\
\text { diversidad } \\
\text { agrupación } \\
\text { clasificación } \\
\text { diseño o plan } \\
\text { elaboración o } \\
\text { ejecución } \\
\text { valoración } \\
\text { comunicación } \\
\text { vivencialidad } \\
\text { funcionalidad } \\
\text { reproducción } \\
\text { industrialización } \\
\text { comercialización } \\
\text { consumo } \\
\text { trascendencia } \\
\text { importancia }\end{array}$ & $\begin{array}{l}\text { SUJETOS } \\
\text { ORGANISMOS } \\
\text { OBJETOS } \\
\text { ESTRUCTURAS } \\
\text { LUGARES } \\
\text { TIEMPOS } \\
\text { RITMOS } \\
\text { IMÁGENES } \\
\text { PERCEPCIONES } \\
\text { SENTIMIENTOS } \\
\text { JUEGOS } \\
\text { ACTITUDES } \\
\text { PRINCIPIOS } \\
\text { CRITERIOS } \\
\text { DECISIONES } \\
\text { EMOCIONES } \\
\text { PENSAMIENTOS } \\
\text { EXPLORACIÓN } \\
\text { INVESTIGACIÓN } \\
\text { CONOCIMIENTO } \\
\text { TÉCNICAS } \\
\text { PROCESOS } \\
\text { ACTIVIDADES } \\
\text { PERSONALIDAD } \\
\text { AMBIENTES } \\
\text { AGRUPACIONES } \\
\text { CULTURAS } \\
\text { COMUNICACIÓN } \\
\text { SITUACIONES } \\
\text { HECHOS } \\
\text { EXPERIENCIAS } \\
\text { CREATIVIDAD } \\
\text { ARTES } \\
\text { TÉCNICAS } \\
\text { CIENCIAS } \\
\text { TECNOLOGÍAS } \\
\text { TEXTUALIDADES } \\
\text { LINGÜÍSTICAS } \\
\text { TEXTUALIDADES } \\
\text { NO } \\
\text { LINGÜÍSTICAS }\end{array}$ & $\begin{array}{l}\text { Naturaleza } \\
\text { Cadena, enlaces, } \\
\text { ciclos, fenómenos, } \\
\text { acciones, cambios, } \\
\text { construcciones, } \\
\text { creaciones, } \\
\text { concomitancias, } \\
\text { transgresiones, } \\
\text { confrontaciones, } \\
\text { crisis, guerras, } \\
\text { conflictos, } \\
\text { expediciones, } \\
\text { migraciones, } \\
\text { inmigraciones, } \\
\text { invasiones, } \\
\text { colonizaciones, } \\
\text { explotaciones, } \\
\text { liberaciones... } \\
\text { percepción } \\
\text { imaginación } \\
\text { afectividad } \\
\text { lúdica } \\
\text { ética } \\
\text { emotividad } \\
\text { operaciones } \\
\text { mentales } \\
\text { tipos de } \\
\text { pensamientos } \\
\text { ciencia } \\
\text { filosofía } \\
\text { técnica } \\
\text { arte } \\
\text { praxis } \\
\text { deportes } \\
\text { lo personal } \\
\text { lo social } \\
\text { lo ambiental } \\
\text { lo cultural } \\
\text { situación } \\
\text { comunicativa } \\
\text { interacción } \\
\text { historial } \\
\text { investigación } \\
\text { tecnología } \\
\text { lenguaje } \\
\text { lo literario }\end{array}$ & $\begin{array}{l}\text { ORIGEN DE... } \\
\text { EVOLUCIÓN DE... } \\
\text { CONSOLIDACIÓN } \\
\text { DESARROLLO } \\
\text { MOVIMIENTO } \\
\text { DIFUSIÓN } \\
\text { DESINTEGRACIÓN } \\
\text { CONTAMINACIÓN } \\
\text { CREACIÓN DE } \\
\text { INSTRUMENTOS } \\
\text { PARA PERCEPCIÓN } \\
\text { DE REALIDAD } \\
\text { FANTASÍA } \\
\text { CIENCIA FICCIÓN } \\
\text { RELIGIONES } \\
\text { CREACIÓN DE } \\
\text { EMPRESAS } \\
\text { CRIITICA } \\
\text { ESPECTÁCULOS } \\
\text { PELÍCULAS } \\
\text { MÚSICA } \\
\text { CONCEPTOS } \\
\text { TEORÍAS } \\
\text { LEYES } \\
\text { ORIGEN DE... } \\
\text { DISCIPLINAS, } \\
\text { MÉTODOS, } \\
\text { ENFOQUES } \\
\text { MODELOS } \\
\text { PROMULGACIONES } \\
\text { CONSTITUCIONES } \\
\text { REGLAMENTACIÓN } \\
\text { ENCUENTROS } \\
\text { REFORMAS } \\
\text { TECNIFICACIÓN } \\
\text { INDUSTRIALIZAR } \\
\text { COMERCIALIZAR } \\
\text { CAPITALIZACIÓN } \\
\text { MODERNIZACIÓN } \\
\text { SISTEMATIZACIÓN } \\
\text { CULTURIZACIÓN } \\
\text { INTERNET } \\
\text { GLOBALIZACIÓN } \\
\text { VIVENCIAS } \\
\text { CELEBRACIONES } \\
\text { CREACIÓN DE } \\
\text { ARTE, TEXTOS }\end{array}$ & $\begin{array}{l}\text { Aquí, acá } \\
\text { allá } \\
\text { arriba } \\
\text { abajo } \\
\text { al lado } \\
\text { dentro } \\
\text { fuera } \\
\text { sobre } \\
\text { debajo } \\
\text { derecha } \\
\text { izquierda } \\
\text { delante de } \\
\text { detrás de } \\
\text { alrededor de } \\
\text { en el centro de } \\
\text { en medio de } \\
\text { en frente de } \\
\text { cerca de } \\
\text { lejos de } \\
\text { por encima de } \\
\text { a través de } \\
\text { norte } \\
\text { sur } \\
\text { oriente } \\
\text { occidente } \\
\text { grados según } \\
\text { latitud } \\
\text { grados según } \\
\text { longitud } \\
\text { en este sitio, lugar } \\
\text { en esta ciudad } \\
\text { en esta región } \\
\text { en este país } \\
\text { en este continente } \\
\text { en este mundo } \\
\text { en este planeta } \\
\text { en esta galaxia } \\
\text { en este universo }\end{array}$ & $\begin{array}{l}\text { ahora, ya } \\
\text { en este momento } \\
\text { en la madrugada } \\
\text { en la mañana } \\
\text { a mediodía } \\
\text { en la tarde } \\
\text { en la noche } \\
\text { ayer } \\
\text { mañana } \\
\text { anteayer } \\
\text { pasado mañana } \\
\text { todos, todas } \\
\text { estas semanas } \\
\text { este fin de semana } \\
\text { esta quincena } \\
\text { este mes } \\
\text { esta estación } \\
\text { este bimestre } \\
\text { este cuatrimestre } \\
\text { este semestre } \\
\text { este año } \\
\text { este aniversario } \\
\text { este bienio } \\
\text { este lustro } \\
\text { esta década } \\
\text { este siglo } \\
\text { este milenio } \\
\text { esta época } \\
\text { más tarde } \\
\text { con frecuencia } \\
\text { nunca jamás } \\
\text { rara vez } \\
\text { cada vez } \\
\text { siempre } \\
\text { un rato } \\
\text { pronto } \\
\text { hace tiempo } \\
\text { antes } \\
\text { después } \\
\text { cuando } \\
\text { ora } \\
\text { tiempo sincrónico } \\
\text { tiempo diacrónico }\end{array}$ \\
\hline
\end{tabular}

Figura 2. Organigrama temático sobre categorías culturales en una heurística de la realidad

Fuente: elaboración propia

\section{Un caso de aplicación de las categorías culturales}

El proceso lector con mira al descubrimiento del texto, a su plan de escritura y a su desarrollo, se ve favorecido por el reconocimiento y uso de categorías culturales; razón por la cual, se instrumentaliza dicho proceso. El análisis textolingüístico desde la exploración del comportamiento gramatical (categorías culturales explícitas/implícitas resaltadas y/o precisadas, lo evidencian (figura 3). 


\section{Texto base: \\ El poder de la población de las grandes urbes (Temas: 1poder; 2población; y 3urbes)}

Durante siglos, las ciudades han sido descritas como aglomeraciones antinaturales, violentas y con elevados costos de vida. $i \mathrm{~A}$ qué se debe entonces la migración en todo el mundo del campo a la ciudad? Investigaciones recientes muestran que las ciudades producen una cantidad mayor de inventos y de oportunidades de desarrollo económico pues los aumentos de población promueven interacciones sociales más frecuentes e intensas. Estas interacciones se correlacionan con tasas más elevadas de innovación y productividad, y suscitan presiones económicas que limpian las ineficiencias: la población se ve forzada a buscar nuevas formas de organización, así como productos y servicios más rentables. (Adaptado de Bettencourt y West, 2011).

\section{Categorías culturales en gramática cultural. ¿Qué dice el texto?}

\begin{tabular}{|c|c|c|c|c|c|c|c|}
\hline $\begin{array}{l}\text { Introductorios } \\
\text { y cohesivos }\end{array}$ & $\begin{array}{l}\text { Sujeto } \\
\text { textual }\end{array}$ & $\begin{array}{c}\text { Núcleo del } \\
\text { predicado } \\
\text { textual }\end{array}$ & Nexos & $\begin{array}{l}\text { Complementos } \\
\text { directos }\end{array}$ & Nexos & $\begin{array}{c}\text { Otros } \\
\text { complementos }\end{array}$ & $\begin{array}{c}\text { Más } \\
\text { complementos }\end{array}$ \\
\hline Durante siglos, & $\begin{array}{l}\text { las ciudades } \\
\text { (Tema3) }\end{array}$ & $\begin{array}{l}\text { han sido des- } \\
\text { critas } \\
\text { (Afirmac.1) }\end{array}$ & como & $\begin{array}{l}\text { aglomeraciones an- } \\
\text { tinaturales, violentas } \\
\text { y con elevados } \\
\text { costos de vida. } \\
\text { (Caracterís.-) }\end{array}$ & & & \\
\hline ¿A qué & & $\begin{array}{l}\text { se debe } \\
\text { (pregunta } \\
\text { problema1) }\end{array}$ & $\begin{array}{l}\text { enton- } \\
\text { ces }\end{array}$ & $\begin{array}{l}\text { la migración } \\
\text { (Tema1a) } \\
\text { (Fenómeno) }\end{array}$ & en & todo el mundo & $\begin{array}{l}\text { del campo a la } \\
\text { ciudad? }\end{array}$ \\
\hline $\begin{array}{l}\text { Investigaciones } \\
\text { recientes }\end{array}$ & & $\begin{array}{l}\text { muestran } \\
\text { (Sustento1) }\end{array}$ & & & & & \\
\hline que & $\begin{array}{l}\text { las ciudades } \\
\text { (Tema3) }\end{array}$ & producen & & $\begin{array}{l}\text { una cantidad mayor } \\
\text { de inventos } \\
\text { (Caracterís.+) } \\
\text { (Causa1 }\end{array}$ & y & $\begin{array}{l}\text { de oportunidades } \\
\text { de desarrollo eco- } \\
\text { nómico } \\
\text { (Caracterís.+) } \\
\text { (Causa2) }\end{array}$ & \\
\hline \multirow[t]{2}{*}{ pues } & $\begin{array}{l}\text { los aumentos } \\
\text { de población } \\
\text { (Tema2) } \\
\text { (Caracterís.+) } \\
\text { (Causa3) }\end{array}$ & promueven & & $\begin{array}{l}\text { interacciones socia- } \\
\text { les más frecuentes e } \\
\text { intensas. } \\
\text { (Tema1b) } \\
\text { (Fenómeno2) }\end{array}$ & & & \\
\hline & $\begin{array}{l}\text { Éstas interac- } \\
\text { ciones } \\
\text { (Tema1b) } \\
\text { (Fenómeno2) }\end{array}$ & $\begin{array}{l}\text { se correlacio- } \\
\text { nan }\end{array}$ & con & $\begin{array}{l}\text { tasas más elevadas } \\
\text { de innovación y } \\
\text { productividad, } \\
\text { (Fenómeno3) }\end{array}$ & & & \\
\hline y & & suscitan & & $\begin{array}{l}\text { presiones econó- } \\
\text { micas }\end{array}$ & & & \\
\hline \multirow[t]{3}{*}{ que } & & limpian & & las ineficiencias: & & & \\
\hline & $\begin{array}{l}\text { La población } \\
\text { (Tema2) }\end{array}$ & $\begin{array}{l}\text { se ve forzada a } \\
\text { buscar }\end{array}$ & & $\begin{array}{l}\text { nuevas formas de } \\
\text { organización } \\
\text { (Fenómeno3) }\end{array}$ & & & \\
\hline & & & $\begin{array}{l}\text { así } \\
\text { como }\end{array}$ & $\begin{array}{l}\text { productos y servi- } \\
\text { cios más rentables. } \\
\text { (Fenómeno4) }\end{array}$ & & & \\
\hline
\end{tabular}

Conclusión. Según el título, se exige un reconocimiento del poder de las poblaciones que a su vez forma parte de las grandes urbes o ciudades. Cuando se precisan las categorías culturales presentes en el texto, el reconocimiento de cómo funciona el mismo, se hace más eficaz. Se puede deducir que el poder de las poblaciones se evidencia en diversos fenómenos como las migraciones, las interacciones, las tasas más elevadas de innovación y productividad, las nuevas formas de organización y, los productos y servicios más rentables que buscan ellas mismas. Las causas de la pregunta problema también se logran concretar. Si no hacemos uso de categorías culturales durante la lectura, la instrumentalización de la información no se concreta fácilmente. La concepción de tema y de característica como categorías culturales se subordina a las exigencias del texto.

Figura 3. Texto y rejilla con aplicación de las categorías culturales

Fuente: elaboración propia. 
La estructura temática tripartita entre poder/ población/urbe hace que el lector busque qué relaciones se presentan entre los tres temas. Se identifica la naturaleza del texto que en este caso es de carácter argumentativo y se precisa la organización textolingüística del texto. Para esta tipología textual, es importante considerar la fuerza argumentativa del texto con la consideración de aspectos como el (los) tema(s) que se aborda(n), la inquietud o el problema que se percibe y el desarrollo de diversas gramáticas presentes en el texto.

\section{Metodología empleada}

El presente estudio de carácter cualitativo imbrica la metodología heurística, la interdisciplinar y la cultural como ya se ha mencionado. Desde la metodología heurística, se optó por reconocer los aspectos reiterativos en el abordaje de objetos de estudio, en cuanto a aquellos que el lector puede representar en su mente, inferir, cuestionar, criticar y aún dialogar. Al documentarlos de forma interdisciplinar, se logró detallar que se trataba de categorías de diversa naturaleza; sin embargo, sí había coincidencia en cuanto a su origen cultural. Por este motivo se generalizó su concepción como categorías culturales.

Por otra parte, en el análisis del texto escrito, desde los aportes de la gramática del texto (López y Vanegas, 2005), se logró observar el comportamiento de dichas categorías culturales en relación con una gramática cultural. Por consiguiente, uno de los aportes de este estudio tiene que ver con el modo como se lee y se escribe desde las categorías culturales y su contribución con la instrumentalización del pensamiento. Las aplicaciones se evidencian en la elaboración de representaciones cognitivas como mentefacto y análisis textolingüístico.

\section{Resultados}

El constructo teórico sobre las categorías culturales representado mediante un mentefacto evidencia cómo se instrumentaliza el proceso escritor de forma organizada, relacionada con un plan de escritura fácilmente ampliable y con dominio autónomo a la hora de profundizar. Categorías que permiten desarrollar el texto escrito sobre un objeto de estudio como es el caso de las mismas categorías culturales.

La explicitación de la aplicación de las categorías culturales en la instrumentalización del proceso lector también se evidencia en la rejilla de análisis de carácter textolingüístico. Su precisión permite generar una lectura más consciente, inferencial, crítica y aún dialógica, como se explicita en la conclusión del análisis.

Cognitiva, cultural y lingüísticamente, las categorías culturales instrumentalizan el pensamiento categorial y las funciones cognitivas de entrada, de elaboración y de salida propuestas por Feuerstein que acontecen en la lectura y la escritura. A continuación se enlistan algunos aspectos del pensamiento y de las funciones cognitivas que se impactan con base en los ejemplos explicitados de mentefacto y análisis textolingüístico que usan las categorías culturales:

- Focaliza la atención hacia temas específicos y sus subtemas (categorías y subcategorías; sujetos y predicados textuales).

- Permite planificar el qué leer y con qué alcance referencial, inferencial o crítico.

- Contextualiza lo que se lee (fuente, autor, contexto espacio-temporal y contexto sociocultural, entre otros).

- Facilita reconocer los casos de cohesión para una mejor comprensión del objeto de estudio y de una gramática textual.

- Ayuda a: organizar la información, seleccionarla, representarla, relacionarla, compararla, inferirla, evidenciarla, clasificarla, comunicarla, filtrarla, resumirla, generalizarla, concebirla y representarla en su complejidad como un constructo (visible en el mentefacto y el análisis textolingüístico). 
Como resultado relevante, la inclusión de la categoría cultural de acontecimiento y acción complementa la propuesta aristotélica y kantiana. Su funcionalidad se hace evidente en el análisis textolingüístico que trasciende la gramática lingüística.

\section{Conclusiones}

El reconocimiento de las categorías culturales en relación con su origen primigenio desde Aristóteles y Kant, y el modo en que han sido aludidas por diversos estudios como productos de la interacción y de la convención, las constituyen en elementos del imaginario cultural y un campo de estudio prolífico y aplicable a diversas disciplinas.

Las categorías culturales, que en realidad constituyen una gramática especial, se presentan en la interacción texto/lector y escritor/texto; se trata, entonces, de evidenciarlas desde el pensamiento inferencial y reconocer su valor en la instrumentalización del pensamiento formal/categorial; y ver su aplicabilidad, a su vez, en la instrumentalización del proceso lector y escritor. Una lectura y escritura más conscientes a la luz de la cultura.

\section{Reconocimientos}

Este artículo presenta resultados del Proyecto de Investigación Institucional "Lineamientos de investigación para la educación superior", financiado por la Universidad de Pamplona (Colombia) y con ejecución de 2018 a 2019.

\section{Referencias bibliográficas}

Aristóteles. (s.f.). Las categorías. Recuperado de http://www.documentacatholicaomnia.eu /03d/384_322,_Aristoteles,_Libro_de_las_Categorias,_ES.pdf

Bajtín, M. (2011). Las fronteras del discurso. Buenos Aires: Las Cuarenta.

Bettencourt, L. y West, G. (2011). Grandes urbes: conseguir más con menos. Revista Investigación y Ciencia, 422, 28-32.
Carabaña, J. y Lamo, E. (1978). La teoría social del interaccionismo simbólico: análisis y valoración crítica. Reis, 1(78), 159-203. Recuperado de https:// dialnet.unirioja.es/descarga/articulo/666889.pdf.

Castoriadis, C. (2002). Figuras de lo pensable (Las encrucijadas del laberinto VI). México: Fondo de Cultura Económica.

De Zubiría, M. y De Zubiría, J. (1998). Biografía del pensamiento. Estrategias para el desarrollo de la inteligencia. Bogotá: Magisterio.

Feuerstein, R. (1993). Modificabilidad Cognitiva y Programa de Enriquecimiento Instrumental. Manual para el alumno y el docente. Madrid: Instituto Superior Pío $\mathrm{X}$.

Halliday, M.A.K. (2013). El lenguaje como semiótica social. México: Fondo de Cultura Económica.

López, A. y Vanegas, D. (2005). El conocimiento del texto lingüístico y su trascendencia en la Didáctica de la Lengua y la Literatura. Bordón, 57(3), 397-405.

López, A., Vanegas, D. y López, M. (2007). Una competencia textolingüística en permanente desarrollo. El Guiniguada, 15-16, 31-42. Recuperado de https:// docplayer.es/20175311-Una-competencia-texto-linguistica-en-permanente-desarrollo.html

Martínez, J. (1988). Modificabilidad cognitiva y programa de enriquecimiento instrumental. Esquemas para la comprensión y práctica del modelo de Reuven Feuerstein. Madrid: Instituto Superior S. Pío X.

Martínez, M. (2002). Hermenéutica y análisis del discurso como método de investigación social. En Paradigma, 23, 1-13.

Merrell, F. (s.f.). Charles Peirce y sus signos. Signos en Rotación, III(181). Recuperado de http://www.unav. es/gep/Articulos/SRotacion3.html.

Ministerio de Educación Nacional (MEN) (1998). Lineamientos curriculares para Lengua Castellana. Santafé de Bogotá: Cooperativa Editorial Magisterio.

Montero, F. (1976) La deducción de las categorías kantianas. Teorema: Revista internacional de Filosofía, 1(2), 249-275. Recuperado de https://dialnet.unirioja.es/descarga/articulo/2046501.pdf.

Pons, X. (2010). La aportación a la psicología social del interaccionismo. Revista eduPsykhé, 9, 23-41.

Van Dijk, T.A. (1980). Texto y contexto. Madrid: Cátedra. 
Vanegas, D. y López, A. (2015a). Experiencia didáctica en el desarrollo de la competencia textolingüística como orientadora de la lectura y la escritura (estudio experimental). Diexpe Experimenta Pedagógicamente, 1, 21-27. Recuperado de https://issuu. com/diexpe/docs/diexpe_2015_1

Vanegas, D. y López, A. (2015b). Heurística de una Didáctica General. Diexpe Experimenta Pedagógicamente, 1, 6-11. Recuperado de https://issuu.com/ diexpe/docs/diexpe_2015_1

Vanegas, D. y Ramón, A.A. (2017). Comunidad y cultura ambiental. Revista Agua, Aire y Suelo, 8(1), $36-43$.
Vanegas, D., Celis, R.A. y Becerra, J.S. (2016). Modelo interdisciplinar de intervención pedagógico-didáctica propulsor de un proceso de enseñanza-aprendizaje de calidad. Revista Universidad y Sociedad, 8(1), 151-158. Recuperado de http://scielo.sld.cu/ pdf/rus/v8n1/rus21116.pdf.

Vanegas, D., Ramón, J.A. y Valencia, J.D. (2015). Aplicación del modelo heurístico significativo en la interpretación de la cultura ambiental. Revista Face, 15(2), 107-116. Recuperado de http://revistas.unipamplona.edu.co/ojs_viceinves/ index.php/FACE/article/view/1913. DOI: https:// doi.org/10.24054/01204211.v2.n2.2015.1913 